\title{
Comparative in silico analysis of chemotaxis system of Campylobacter fetus.
}

Dina Fahmy, Christopher J. Day and Victoria Korolik*

Institute for Glycomics, Griffith University Gold Coast Campus, Griffith University, Queensland, Australia, 4222

*For correspondence. E-mail v.korolik@griffith.edu.au; Tel. (+61) 75552 8321; Fax (+61) 75552 8908.

Running title: $C$. fetus chemotaxis pathway genes.

\begin{abstract}
Chemoreceptor and chemotaxis signal transduction cascade genes of C. fetus subsp. fetus 8240 show high level of similarity to that in $C$. jejuni and appears to include sixteen diverse transducer-like protein $(t l p)$ genes that appear similar to nine of the twelve tlp genes in the $C$. jejuni NCTC 11168 with a percent identity ranging from $15 \%$ to $50 \%$. Sixteen putative $C$. fetus 82-40 tlp genes belong to three classes: A, B and C, as well as an aerotaxis gene, based on their predicted structure. C. fetus fetus 82-40 chemoreceptor and chemotaxis signal transduction pathway genes have close phylogenetic relationship of chemotaxis genes among Campylobacteraceae and Helicobacteraceae
\end{abstract}

Keywords: Chemotaxis; Chemosensory receptors; Campylobacter fetus 


\section{Introduction}

The bacteria belonging to species Campylobacter fetus are recognized as an important animal and human pathogens (Vandamme et al. 1991). C. fetus can be divided into two subspecies, C. fetus subsp. venerealis (CFV) and C. fetus subsp. fetus (CFF) and includes an intermediate of $C$. fetus subsp venerealis, designated biovar intermedius (CVI) (Veron and Chatelai.R 1973). CFV shows a strong tropism for the bovine genital tract causing bovine genital campylobacteriosis (BGC), a disease that causes the destruction of the cattle's embryo early in gestation (Garcia et al. 1983). Human infections with this subspecies are not common (Thompson and Blaser 1995). CFF on the other hand can cause infections in humans and animals including, cattle, goats, pigs, horses, fowl and reptiles and can cause abortion in sheep and cattle (Dennis 1975; Harvey and Greenwood 1985; Garcia et al. 1983; Meinershagen et al. 1965; Tu et al. 2004; Watson et al. 1967).

Although the mechanisms of campylobacter pathogenicity are poorly understood, motility and chemotaxis have been shown to be important for the initiation of the disease process for Campylobacter species (Hugdahl et al. 1988; Ferrero and Lee 1988; Lee et al. 1986; Szymanski et al. 1995; Takata et al. 1992; Terry et al. 2005).

In silico analysis of the genome sequence of C. jejuni NCTC 11168 (Marchant et al. 2002), revealed that in $C$. jejuni, some of the key signal transduction chemotaxis proteins, such as CheW and CheY, are conserved, while others show differences to those found in $E$. coli. CheB protein lacks a CheY-like receiver domain while CheA protein contains an additional C-terminal domain homologous to CheY. C. jejuni also encodes a CheV protein, similar to CheV in B. subtilis (Fredrick and Helmann 1994) and a putative analogue of CheZ like Helicobacter pylori (Terry et al. 2006).

Ten chemoreceptor genes of $C$. jejuni NCTC 11168 (designated transducer-like proteins Tlps) and two aerotaxis gene homologs were structurally categorized into three 
groups, A, B, and C (Marchant et al. 2002). To date there are seven group A sensory receptors have been described for $C$. jejuni: Tlp1, Tlp2, Tlp3, Tlp4, Tlp7, Tlp10 and Tlp11. It is interesting to note that although the DNA and amino acid sequences of the group A Tlps are highly conserved, the presence of these receptors in $C$. jejuni strains is highly variable with only Tlp1 and Tlp10 consistently present in all strains described to date (Korolik and Ketley, 2008) Due to the typical three-domain structure of the group A chemoreceptors (a variable periplasmic sensory domain and conserved transmembrane and cytoplasmic signaling domains), these receptors are considered to be responsible for sensing ligands external to the cell, similar to E. coli (Falke, 1997). It is yet to be established what role a particular subset of sensory receptors may play in colonization of animal hosts or in virulence of $C$. jejuni stains. To date the only receptor-ligand interaction for the Tlp1 (CcaA) aspartate sensory receptor, has been demonstrated (Hartley-Tassell et al. 2010). This receptor was also shown to signal though the $\mathrm{CheV}$, rather then $\mathrm{CheW}$ in the sensory receptor complex. In addition, interactions were detected between the Tlps 4, 6 and 8 and CheV, via global twohybrid analysis, however, in this instance, specific interactions were not further explored (de rita). These data indicates that in $C$. jejuni, the sensory receptor complex, at least for periplasmic sensory receptors, uses $\mathrm{CheV}$, and not $\mathrm{CheW}$ as scaffolding protein in signal transduction. Chemoreceptor group B contains one cytoplasmic receptor homologue (Tlp9 or CetA) and group C contains Tlps 5, 6, 8, that are considered to be receptor proteins able to detect physiological cytoplasmic signals (Marchant).

\section{Chemosensory receptors of $C$. fetus.}

Comparison of the of the published sequences of C. jejuni NCTC 11168 Groups A, B, C Tlps and aerotaxis receptor proteins with those encoded by the genomic sequence of $C$. fetus 82-40 (using the Clustal W, BioEdit sequence alignment editor and TMHMM2, based on Hidden Markov Model) revealed presence of putative orthologs of chemotaxis receptor 
genes in C. fetus 82-40 genome. Sixteen tlp-like genes in C. fetus 82-40 genome appeared orthologous to nine of the twelve tlp genes in the $C$. jejuni NCTC 11168 with a percent identity ranging from $15 \%$ up to $50 \%$ (similarity range $33 \%$ to $72 \%$ - protein-protein comparison; Table 1). The full amino acid sequences of four $C$. fetus $82-40$ putative Tlp proteins, CFF82-40-1041, CFF82-40-0185, CFF82-40-1645 and CFF8240-0065 showed $50 \%, 34 \%, 32 \%$ and $15 \%$ identity and $72 \%, 55 \%, 52 \%$ and $33 \%$ similarity respectively with the protein sequence from the same gene, $C$. jejuni NCTC11168-1506c (tlpl; Table 1). The highest percent identity 50\% (similarity 72\%), with C. jejuni NCTC11168-1506c tlpl was present in CFF82-40-1041 (Table 1). Similarly, four other C. fetus 82-40 putative chemoreceptor proteins; CFF82-40-1305, CFF82-40-0190, CFF82-40-1698 and CFF82-401307 showed highest level of similarity with a single $C$. jejuni Tlp protein, Tlp4 (NCTC11168-0262c), whereas genes CFF82-40-0511 and CFF82-40-0975 revealed similarity with C. jejuni Tlp6 (NCTC11168-Cj0448c; Table 1). Although CFF82-40-1041 showed the highest percent similarity with $C$. jejuni aspartate receptor Tlp1 (NCTC111681506c), and could be the putative C. fetus 82-40 tlpl ortholog, similarity levels do not exclude the possibility that either one of the three $C$. fetus 82-40 tlp genes, CFF8240-0185, CFF82-40-1645 and CFF82-40-0065 could instead be the ortholog of C. jejuni NCTC111681506c (tlp1; Table 1). Experimental evidence is necessary in order to verify the ligand binding specificity of each of these $C$. fetus $82-40$ chemoreceptors. These data, never the less, allow to speculate that $C$. fetus may be able to respond to a wider range of ligands than $C$. jejuni or indeed may have some redunduncy in receptor specificty, where two to four receptors may be able to sense the same ligand, perhaps providing signal amplification for detection of essential nutrients.

It should be noted that the manual scoring of pair-wise alignments for both full coding sequences and sensory domain coding sequences of the C. fetus 82-40 receptor genes with 
their respective orthologs in the tested Epsilon proteobacteria genomes indicated an interesting discrepancy with BLASTp analysis. In the case of 11 of C. fetus 8240 tlp genes, their sequences revealed identity with the same corresponding C. jejuni NCTC11168 Tlp sequence, irrespective of whether the complete amino acid sequence was used for analysis, or only the sequence of the periplasmic sensory domain. However, five of the sixteen Tlp sequences (CFF82-40-0185, CFF82-40-1645, CFF82-40-1227, CFF82-40-0139 and CFF8240-0065) aligned with a different protein of $C$. jejuni NCTC11168 when the sensory domain sequences only were compared (Table 2). When the periplasmic sensory domains were aligned to proteins encoded by the $C$. jejuni NCTC11168 genome, CFF82-40-1645, CFF8240-1227 and CFF82-40-0065 no longer aligned with $C$. jejuni Tlps, instead aligning with an acid membrane protein, putative ATP/GTP binding protein and restriction modification enzyme respectively. This finding underlines the importance of manual and reciprocal sequence alignment analysis for maximum accuracy. It is particularly pertinent for genes with multiple domains, where some domains may be highly conserved due to their function, such as signalling domains of $t l p$ genes and signalling proteins in general. In this case, the high level of similarity among signalling domains of chemosensory proteins, had obscured the fact that their sensory domains, which determine receptor-ligand specificity, were each similar to a different receptor or another protein with lower overall gene similarity.

Comparison of C. fetus 82-40 chemosensory receptors with the genomes of other Epsilon proteobacteria as well as with two representative genomes of the family Helicobacteraceae; H. pylori 26695 and W. succinogenes DSM 1740 (Table 3) showed that percent identity of $C$. fetus $82-40$ tlp genes with their orthologs in all the examined genomes is in the range of $12 \%$ to $72 \%$ (similarity range $32 \%$ to $86 \%$ - protein-protein comparison, Table 3). Conversely, the periplasmic sensory domains of the Tlps show high degree of 
interspecies and intraspecies variablility, necesitating independent comparisons of all group A $t l p$ genes sensory domains as was performed for $C$. jejuni.

\section{Signal transduction pathway of $C$. fetus.}

Interestingly, similar to that in C. jejuni NCTC11168 genome (Parkhill et al. 2000), most of the tlp genes as well as two of the chemotaxis pathway genes; cheZ analogue and the RR cheY in C. fetus 82-40 genome were scattered in the genome and three chemotaxis genes cheA, cheW and cheV, as well as cheR, cheB pair, are contiguous. The comparative in silico analysis revealed that $C$. fetus $82-40$ chemotaxis signal transduction pathway genes (cheA, che $\mathrm{W}$, che $\mathrm{Y}$, che $\mathrm{V}$, che $\mathrm{B}$ che $\mathrm{R}$ and cheZ orthologs) had the expected high level of similarity with their corresponding orthologs in the $C$. jejuni NCTC11168 genome (Parkhill et al. 2000), for example CFF82-40-0331 gene (cheA) showed 79\% identity (91\% similarity protein-protein comparison) with Cj11168-0284c (cheA) (Table 1).

C. fetus 82-40 signal transduction genes are also similar to their respective orthologs in genomes of Epsilon proteobacteria, C. jejuni 84-25 (JCVI-CMR), C. coli RM2228, C. lari RM2100, C. upsaliensis RM3195 (Fouts et al. 2005) and the related Epsilon proteobacteria H. pylori 26695 (Tomb et al. 1997) and W. succinogenes DSM 1740 (Baar et al. 2003). All of the signal transduction genes orthologs were highly conserved in the examined genomes of C. jejuni 84-25, C. coli RM2228, C. lari RM2100, C. upsaliensis RM3195 and W. succinogenes DSM 1740 (Table 1 and 3), indicating functional conservation of the chemotaxis signal transduction cascade in Epsilon proteobacteria.

\section{Phylogenetic relationships of chemosensory receptors of $C$. fetus with the Epsilon proteobacteria chemosenory receptors.}

Close phylogenetic relationships exist between the sixteen $C$. fetus $82-40$ tlp genes with their corresponding orthologs in the genomes of Campylobacteraceae, (C. jejuni 
NCTC11168, C. jejuni 84-25, C. coli RM2228, C. lari RM2100, C. upsaliensis RM3195) and Helicobacteraceae (H. pylori 26696, W. succinogenes DSM 1740), where clusters with a bootstrap value greater than or equal to $75 \%$ were defined as confirmed subgroups (Tripathi and Sowdhamini 2008). Unexpectedly, clustering patterns of the sixteen C. fetus 82-40 tlp genes were different. Most $C$. fetus Tlps clustered with the other Campylobacteraceae in various relationships (Figure 1a and b for examples; Figures S1-3), however, some of the receptors clustered closer to $W$. succinogenes DSM 1740 (Figure 1c for example; Figure S4). Three of the C. fetus tlp genes, CFF8240-1041, CFF8240-1645 and CFF8240-0322, clustered with their respective orthologues in both $C$. jejuni NCTC11168 and C. jejuni 8425, with 97\%, $86 \%$ and $79 \%$ boostrap values respectively (Figure 1 and Figure S1). CFF8240-0065 tlp gene fell into a cluster with $C$. upsaliensis RM3195 CUP-1515 and C. coli RM2228 CCO0518 (Figure S2) and one of the sixteen C. fetus 8240 tlp genes, CFF8240-0139, grouped with W. succinogenes DSM 1740 WS-1861, with C. coli RM2228 CCO-1600 and C. jejuni NCTC11168-1492c with bootstrap support of 93\% (Figure S3). Receptor gene CFF82401223, clustered with its corresponding orthologue in C. lari RM2100 CLA-0003 with 78\% bootstrap support (Figure S4) and CFF8240-1227 clustered with two of its corresponding orthologues in both $C$. lari RM2100 CLA-0183 and W. succinogenes DSM 1740 WS-0843 with $53 \%$ bootstrap support (Figure 1). It is also interesting to note that C. fetus tlp 8240 genes CFF8240-0511 clustered with W. succinogenes DSM 1740 WS-0128 and WS-0696 with $100 \%$ and $85 \%$ bootstrap support (Figure 1c).

Phylogenetic analysis of the $C$. fetus $82-40 \mathrm{tlp}$ and chemotaxis pathway protein sequences has consequently identified seven different phylogenetic relationships for C. fetus 82-40 genes. C. fetus chemosensory genes. Unfortunately, until the ligand specificty of each of the chemosensory receptors is identified, it is difficult to explain why $C$. fetus genome encodes 
such diverse range of sensory receptors. This underlines the fact that it is not possible to assign function to chemosensory receptor homologue or orthologue genes based on sequence similarities and that experimental data is required to determine the specificity of receptorligand interactions. Recently identified $C$. jejuni aspartate receptor (Tlp1), with $0 \%$ similarity to the sensory domain amino acid sequnce to the well charachterised E. coli aspartate receptor ( hartley) provides an excellent exmple of proteins with different animo acid composition forming a similar tertiary structure able to bind the same ligand. The diversity of the $C$. fetus sensory receptor gene set appears to be an excellent example of the mozaic nature of bacterial genomes where different sensory genes were likely to have been collected over time from many related organisms to allow survival in various environmental niches and to move to different hosts to expand the host range. The apparent diversity of $C$. fetus chemotsensory genes could allow for the differnetial tissue tropism of this bacteria being able to colonise/infect the animal intesinal tract as well as the genital tract of cattle.

\section{ACKNOWLEDGMENTS}

Dina Fahmy's is supported by the Griffith University International Postgraduate Research Scholarship (GUIPRS). Christopher Day is supported by a Griffith University Postdoctoral Research Fellowship. 


\section{REFERENCES}

Baar C, Eppinger M, Raddatz G, Simon J, Lanz C, Klimmek O, Nandakumar R, Gross R, Rosinus A, Keller H, Jagtap P, Linke B, Meyer F, Lederer H, Schuster SC (2003) Complete genome sequence and analysis of Wolinella succinogenes. Proc Natl Acad Sci U S A 100 (20):11690-11695. doi:10.1073/pnas.1932838100

1932838100 [pii]

Dennis SM (1975) Perinatal lamb mortality in Western Australia: 5. Vibrionic infection. Australian veterinary journal 51 (1):11-13

Ferrero RL, Lee A (1988) Motility of Campylobacter jejuni in a viscous environment: comparison with conventional rod-shaped bacteria. J Gen Microbiol 134 (1):53-59

Fouts DE, Mongodin EF, Mandrell RE, Miller WG, Rasko DA, Ravel J, Brinkac LM, DeBoy RT, Parker CT, Daugherty SC, Dodson RJ, Durkin AS, Madupu R, Sullivan SA, Shetty JU, Ayodeji MA, Shvartsbeyn A, Schatz MC, Badger JH, Fraser CM, Nelson KE (2005) Major structural differences and novel potential virulence mechanisms from the genomes of multiple campylobacter species. PLoS Biol 3 (1):e15. doi:10.1371/journal.pbio.0030015

Fredrick KL, Helmann JD (1994) Dual chemotaxis signaling pathways in Bacillus subtilis: a sigma D-dependent gene encodes a novel protein with both CheW and CheY homologous domains. J Bacteriol 176 (9):2727-2735

Garcia MM, Ruckerbauer GM, Eaglesome MD, Boisclair WE (1983) Detection of Campylobacter fetus in artificial insemination bulls with a transport enrichment medium. Can J Comp Med 47 (3):336-340

Hartley-Tassell LE, Shewell LK, Day CJ, Wilson JC, Sandhu R, Ketley JM, Korolik V (2010) Identification and characterization of the aspartate chemosensory receptor of Campylobacter jejuni. Mol Microbiol 75 (3):710-730. doi:MMI7010 [pii]

10.1111/j.1365-2958.2009.07010.x

Harvey S, Greenwood JR (1985) Isolation of Campylobacter fetus from a pet turtle. J Clin Microbiol 21 (2):260-261

Hugdahl MB, Beery JT, Doyle MP (1988) Chemotactic behavior of Campylobacter jejuni. Infect Immun 56 (6):1560-1566

Korolik V, Ketley JM (2008) Campylobacter chemosensory pathway. In: Nachamkin I, M SC, Blaser MJ (eds) Campylobacter. American Society for Microbiology, Washington, DC: pp 351-366

Krogh A, Larsson B, von Heijne G, Sonnhammer EL (2001) Predicting transmembrane protein topology with a hidden Markov model: application to complete genomes. J Mol Biol 305 (3):567-580. doi:10.1006/jmbi.2000.4315

S0022-2836(00)94315-8 [pii]

Lee A, O'Rourke JL, Barrington PJ, Trust TJ (1986) Mucus colonization as a determinant of pathogenicity in intestinal infection by Campylobacter jejuni: a mouse cecal model. Infect Immun 51 (2):536-546

Marchant J, Wren B, Ketley J (2002) Exploiting genome sequence: predictions for mechanisms of Campylobacter chemotaxis. Trends Microbiol 10 (4):155-159

Meinershagen WA, Waldhalm DG, Frank FW, Scrivner LH (1965) Magpies as a reservoir of infection for ovine vibriosis. J Am Vet Med Assoc 147 (8):843-845

Parkhill J, Wren BW, Mungall K, Ketley JM, Churcher C, Basham D, Chillingworth T, Davies RM, Feltwell T, Holroyd S, Jagels K, Karlyshev AV, Moule S, Pallen MJ, Penn CW, Quail MA, Rajandream MA, Rutherford KM, van Vliet AH, Whitehead S, Barrell BG (2000) The genome sequence of the food-borne pathogen Campylobacter 
jejuni reveals hypervariable sequences. Nature 403 (6770):665-668. doi: $10.1038 / 35001088$

Saitou N, Nei M (1987) The neighbor-joining method: a new method for reconstructing phylogenetic trees. Mol Biol Evol 4 (4):406-425

Sambrook J, Fritsch EF, Maniatis T (1989) Molecular cloning: a laboratory manual. 2nd edn. Cold Spring Harbor Laboratory Press, Cold Spring Harbor, N.Y.

Szymanski CM, King M, Haardt M, Armstrong GD (1995) Campylobacter jejuni motility and invasion of Caco-2 cells. Infect Immun 63 (11):4295-4300

Takata T, Fujimoto S, Amako K (1992) Isolation of nonchemotactic mutants of Campylobacter jejuni and their colonization of the mouse intestinal tract. Infect Immun 60 (9):3596-3600

Tamura K, Dudley J, Nei M, Kumar S (2007) MEGA4: Molecular Evolutionary Genetics Analysis (MEGA) software version 4.0. Mol Biol Evol 24 (8):1596-1599

Terry K, Go AC, Ottemann KM (2006) Proteomic mapping of a suppressor of nonchemotactic cheW mutants reveals that Helicobacter pylori contains a new chemotaxis protein. Mol Microbiol 61 (4):871-882

Terry K, Williams SM, Connolly L, Ottemann KM (2005) Chemotaxis plays multiple roles during Helicobacter pylori animal infection. Infect Immun 73 (2):803-811

Thompson SA, Blaser MJ (1995) Isolation of the Helicobacter pylori recA gene and involvement of the recA region in resistance to low $\mathrm{pH}$. Infect Immun 63 (6):21852193

Tomb JF, White O, Kerlavage AR, Clayton RA, Sutton GG, Fleischmann RD, Ketchum KA, Klenk HP, Gill S, Dougherty BA, Nelson K, Quackenbush J, Zhou L, Kirkness EF, Peterson S, Loftus B, Richardson D, Dodson R, Khalak HG, Glodek A, McKenney K, Fitzegerald LM, Lee N, Adams MD, Hickey EK, Berg DE, Gocayne JD, Utterback TR, Peterson JD, Kelley JM, Cotton MD, Weidman JM, Fujii C, Bowman C, Watthey L, Wallin E, Hayes WS, Borodovsky M, Karp PD, Smith HO, Fraser CM, Venter JC (1997) The complete genome sequence of the gastric pathogen Helicobacter pylori. Nature 388 (6642):539-547

Tripathi LP, Sowdhamini R (2008) Genome-wide survey of prokaryotic serine proteases: analysis of distribution and domain architectures of five serine protease families in prokaryotes. BMC Genomics 9:549

Tu ZC, Zeitlin G, Gagner JP, Keo T, Hanna BA, Blaser MJ (2004) Campylobacter fetus of reptile origin as a human pathogen. J Clin Microbiol 42 (9):4405-4407

van Bergen MA, Dingle KE, Maiden MC, Newell DG, van der Graaf-Van Bloois L, van Putten JP, Wagenaar JA (2005) Clonal nature of Campylobacter fetus as defined by multilocus sequence typing. J Clin Microbiol 43 (12):5888-5898

Vandamme P, Falsen E, Rossau R, Hoste B, Segers P, Tytgat R, De Ley J (1991) Revision of Campylobacter, Helicobacter, and Wolinella taxonomy: emendation of generic descriptions and proposal of Arcobacter gen. nov. Int J Syst Bacteriol 41 (1):88-103

Veron M, Chatelai.R (1973) Taxonomic Study of Genus Campylobacter Sebald and Veron and Designation of Neotype Strain for Type Species, Campylobacter-Fetus (Smith and Taylor) Sebald and Veron. International Journal of Systematic Bacteriology 23 (2):122-134

Watson WA, Hunter D, Bellhouse R (1967) Studies on vibrionic infection of sheep and carrion crows. Vet Rec 81 (10):220-225 
Table 1. Comparison of sequence identity and similarity of the chemoreceptor and chemotaxis pathway genes in C. fetus 82-40, C. jejuni NCTC 11168 and $C$. jejuni 84-25

\begin{tabular}{|c|c|c|c|c|c|}
\hline $\begin{array}{l}\text { Chemotaxis } \\
\text { genes }\end{array}$ & $\begin{array}{l}\text { C. fetus 82-40 } \\
\text { CFF82-40 }\end{array}$ & $\begin{array}{l}\text { C. jejuni NCTC } 11168 \\
\text { Cj11168 }\end{array}$ & $\% \mathrm{I} / \mathrm{S}$ & $\begin{array}{l}\text { C. jejuni 84-25 } \\
\text { CJJ84-25 }\end{array}$ & $\% \mathrm{I} / \mathrm{S}$ \\
\hline \multirow{11}{*}{ Group_A } & 1041 & $1506 \mathrm{c}(\mathrm{tlp} 1)$ & $50 / 72$ & 1589 & $53 / 75$ \\
\hline & 1305 & 0262 (tlp4) & $40 / 64$ & 0173 & $38 / 62$ \\
\hline & 0190 & $0262(\operatorname{tlp} 4)$ & $41 / 65$ & 0173 & $37 / 60$ \\
\hline & 0562 & 0952 (tlp7) & $44 / 70$ & 0982 & $44 / 71$ \\
\hline & 1698 & 0262 (tlp4) & $40 / 65$ & 0173 & $38 / 61$ \\
\hline & 0185 & $1506 \mathrm{c}(\mathrm{tlp} 1)$ & $34 / 55$ & 1589 & $32 / 52$ \\
\hline & 1645 & $1506 \mathrm{c}(\mathrm{tlp} 1)$ & $32 / 52$ & 1589 & $42 / 62$ \\
\hline & 1227 & 1564 (tlp3) & $29 / 51$ & 0173 & $29 / 51$ \\
\hline & 0139 & $1492 \mathrm{c}$ & $18 / 37$ & 0173 & $17 / 38$ \\
\hline & 0065 & $1506 \mathrm{c}(\mathrm{tlp} 1)$ & $15 / 33$ & 1589 & $14 / 32$ \\
\hline & 1307 & $0262(\mathrm{tlp} 4)$ & $40 / 65$ & 0173 & $36 / 58$ \\
\hline Group_A/B & 1223 & 0019c (tlp10) & $22 / 50$ & 0043 & $20 / 46$ \\
\hline \multirow[t]{3}{*}{ Group_C } & 0975 & 0448c (tlp6) & $28 / 56$ & 0472 & $47 / 69$ \\
\hline & 0322 & 1110c (tlp8) & $77 / 89$ & 1138 & $78 / 89$ \\
\hline & 0511 & 0448c (tlp6) & $36 / 62$ & 0472 & $22 / 36$ \\
\hline Aer & 1012 & $1189^{1}$ & $44 / 64$ & 1214 & $43 / 64$ \\
\hline cheW & 0332 & $0283 c$ & $41 / 68$ & 0307 & $69 / 84$ \\
\hline cheA & 0331 & $0284 \mathrm{c}$ & 79/91 & 0308 & $79 / 90$ \\
\hline cheY & 1193 & $0643^{2}$ & $41 / 68$ & 0676 & $41 / 68$ \\
\hline che B & 0805 & $0924 \mathrm{c}$ & $48 / 73$ & 0946 & $72 / 48$ \\
\hline che $\mathrm{R}$ & 0803 & $0923 c$ & $43 / 66$ & 0945 & $43 / 65$ \\
\hline che $\mathrm{V}$ & 0330 & $0285 c$ & $70 / 88$ & 0309 & $87 / 69$ \\
\hline cheZ_H $\mathbf{H}^{4}$ & 1051 & $0700^{3}$ & $57 / 75$ & $0732^{\mathrm{c}}$ & $87 / 69$ \\
\hline
\end{tabular}

${ }^{1}$ : cetB, ${ }^{2}$ : cbrR (Campylobacter bile resistance Regulator) protein, a two-component response regulator,

${ }^{3}$ :hypothetical protein, ${ }^{4}: \mathrm{H}:$ homolog, \%I/S Identical / Similar amino acids. 
Table 2 Five putative $C$. fetus tlp genes (full coding region and sensory domain (SD) with their corresponding orthologous $C$. jejuni NCTC 11168 genes

\begin{tabular}{|c|c|c|c|}
\hline Serial & $\begin{array}{l}\text { C. fetus 82-40 } \\
\text { CFF82-40 }\end{array}$ & $\begin{array}{l}\text { C. jejuni NCTC } 11168 \\
\text { Cj11168 }\end{array}$ & $\% \mathrm{I} / \mathrm{S}$ \\
\hline \multirow[t]{3}{*}{1} & 0185 & $1506 \mathrm{c}(\mathrm{tlp} 1)$ & $34 / 55$ \\
\hline & SD & 1506c (tlp1) SD & $11 / 24$ \\
\hline & SD & $1564(\operatorname{tlp} 3)$ & $11 / 27$ \\
\hline \multirow[t]{3}{*}{2} & 1645 & 1506c (tlp1) & $32 / 52$ \\
\hline & SD & 1506c (tlp1) SD & $12 / 29$ \\
\hline & SD & $1363^{a}$ & $24 / 49$ \\
\hline \multirow[t]{3}{*}{3} & 1227 & $1564(\mathrm{tlp} 3)$ & $29 / 51$ \\
\hline & SD & 1564 (tlp3) SD & $11 / 25$ \\
\hline & SD & $0412^{b}$ & $24 / 46$ \\
\hline \multirow[t]{3}{*}{4} & 0139 & $1492 c$ & $18 / 37$ \\
\hline & \multirow[t]{2}{*}{ SD } & 1492c_no_SD & N/A \\
\hline & & 0144 & $17 / 37$ \\
\hline \multirow[t]{3}{*}{5} & 0065 & 1506c (tlp1) & $15 / 33$ \\
\hline & SD & 1506c (tlp1) SD & $17 / 29$ \\
\hline & SD & $1051 c^{c}$ & $27 / 47$ \\
\hline
\end{tabular}

${ }^{\mathrm{a}}$ : acid membrane antigen $\mathrm{A},{ }^{\mathrm{b}}$ :putative ATP/GTP binding protein, ${ }^{\mathrm{c}}$ : restriction modification enzyme $c j e \mathrm{I} . \quad \mathrm{N} / \mathrm{A}$ : not applicable, \%I/S Identical / Similar amino acids. 
Table 3. Comparative analysis of sequence identity and similarity of chemoreceptor and chemotaxis pathway genes in C. fetus 82-40, C. coli RM2228,

C.lari RM2100 and C.upsaliensis RM3195, H. pylori 26695 and W. succinogenes DSM 1740

\begin{tabular}{|c|c|c|c|c|c|c|c|c|c|c|c|}
\hline $\begin{array}{l}\text { Chemotaxis } \\
\text { genes }\end{array}$ & $\begin{array}{l}\text { C. fetus 82-40 } \\
\text { CFF82-40 }\end{array}$ & $\begin{array}{l}\text { C. coli } \\
\text { RM2228 } \\
\text { CCO }\end{array}$ & $\% \mathrm{I} / \mathrm{S}$ & $\begin{array}{l}\text { C. lari } \\
\text { RM2100 } \\
\text { CLA }\end{array}$ & $\% \mathrm{I} / \mathrm{S}$ & $\begin{array}{l}\text { C.upsaliensis } \\
\text { RM3195 } \\
\text { CUP }\end{array}$ & $\% \mathrm{I} / \mathrm{S}$ & $\begin{array}{l}\text { H. pylori } 26695 \\
\text { HP }\end{array}$ & $\% \mathrm{I} / \mathrm{S}$ & $\begin{array}{l}\text { W. succinogenes } \\
\text { DSM } 1740 \\
\text { WS }\end{array}$ & $\% \mathrm{I} / \mathrm{S}$ \\
\hline \multirow{21}{*}{ Group_A } & 1041 & 0334 (tlpA) & $52 / 77$ & 0356 (tlpA) & $38 / 58$ & $1752(\mathrm{tlpA})$ & $45 / 67$ & 0099 (tlpA) & $31 / 56$ & 0864 & $33 / 58$ \\
\hline & 1305 & $1678(\operatorname{tlpA})$ & $39 / 62$ & $0135(\mathrm{tlpA})$ & $39 / 64$ & 1790 (tlpA) & $40 / 62$ & 0082 (tlpC) & $30 / 59$ & 1333 & $43 / 69$ \\
\hline & 0190 & 1678 (tlpA) & $38 / 60$ & 0135 (tlpA) & $41 / 66$ & $1124(\operatorname{tlpA})$ & $40 / 62$ & $0082(\mathrm{tlpC})$ & $29 / 57$ & 1333 & $34 / 56$ \\
\hline & 0562 & $0943^{a}$ & $36 / 68$ & 0908 (tlpB) & $40 / 71$ & $0527^{\mathrm{f}}$ & $39 / 64$ & $0103(\mathrm{tlpB})^{\mathrm{h}}$ & $21 / 48$ & 2114 & $30 / 62$ \\
\hline & 1698 & $1678(\mathrm{tlpA})$ & $37 / 58$ & 0135 (tlpA) & $41 / 67$ & $1124(\operatorname{tlpA})$ & $39 / 61$ & 0099 (tlpA) & $30 / 55$ & 1333 & $33 / 54$ \\
\hline & 0185 & $1678(\mathrm{tlpA})$ & $32 / 52$ & 0356 (tlpA) & $34 / 52$ & $1790(\operatorname{tlpA})$ & $34 / 52$ & 0099 (tlpA) & $29 / 49$ & 1333 & $37 / 58$ \\
\hline & 1227 & 0334 (tlpA & $29 / 48$ & 0183 & $26 / 46$ & 1790 (tlpA) & $30 / 51$ & 0099 (tlpA) & $26 / 53$ & 0843 & $37 / 64$ \\
\hline & 0139 & 1600 & $17 / 36$ & $0135(\operatorname{tlpA})$ & $16 / 38$ & $1790(\mathrm{tlpA})$ & $14 / 33$ & $0082(\operatorname{tlpC})$ & $12 / 32$ & $1861^{k}$ & $17 / 36$ \\
\hline & 0065 & 0518 & $40 / 68$ & 0962 & $14 / 36$ & $1515^{\mathrm{g}}$ & $42 / 68$ & 0099 (tlpA) & $14 / 34$ & 0859 & $43 / 68$ \\
\hline & 1307 & 1678 (tlpA & $38 / 61$ & 0135 (tlpA) & $39 / 61$ & $1790(\operatorname{tlpA})$ & $41 / 63$ & 0099 (tlpA) & $30 / 53$ & 1333 & $38 / 61$ \\
\hline & 1041_SD & 0334 (tlpA) & $32 / 57$ & $0356(\operatorname{tlpA})$ & $16 / 34$ & $1752(\operatorname{tlpA})$ & $34 / 59$ & 0099 (tlpA) & $14 / 37$ & 0864 & $15 / 35$ \\
\hline & 1305_SD & $1678(\operatorname{tlpA})$ & $20 / 47$ & 0135 (tlpA) & $23 / 47$ & $1790(\operatorname{tlpA})$ & $22 / 44$ & $0082(\operatorname{tlpC})$ & $17 / 37$ & 1333 & $17 / 36$ \\
\hline & 0190_SD & $1678(\mathrm{tlpA})$ & $26 / 55$ & 0135 (tlpA) & $24 / 52$ & $1124(\operatorname{tlpA})$ & $21 / 43$ & $0082(\mathrm{tlpC})$ & $13 / 36$ & 1333 & $17 / 39$ \\
\hline & 0562_SD & $0943 a$ & $36 / 71$ & 0908 (tlpB) & $39 / 66$ & $0527 \mathrm{~b}$ & $38 / 66$ & 0103 (tlpBh) & $7 / 29$ & 2114 & $4 / 6$ \\
\hline & $0185 \_S D$ & 1678 (tlpA) & $11 / 27$ & $0356(\mathrm{tlpA})$ & $16 / 31$ & $1790(\operatorname{tlpA})$ & $12 / 21$ & 0099 (tlpA) & $12 / 27$ & 1333 & $16 / 36$ \\
\hline & $1645 \mathrm{SD}$ & $1678(\operatorname{tlpA})$ & $13 / 29$ & $0356(\mathrm{tlpA})$ & $16 / 32$ & $1124(\operatorname{tlpA})$ & $10 / 22$ & 0099 (tlpA) & $14 / 27$ & 1333 & $14 / 31$ \\
\hline & 1227_SD & 0334 (tlpA) & $16 / 30$ & 0183 & $10 / 23$ & $1790(\operatorname{tlpA})$ & $14 / 29$ & 0099 (tlpA) & $11 / 26$ & 0843 & $13 / 36$ \\
\hline & 0139_SD & 1600 & $12 / 32$ & 0135 (tlpA) & $19 / 44$ & $1790(\operatorname{tlpA})$ & $14 / 33$ & 0082 (tlpC) & $14 / 37$ & $1861 d$ & $12 / 25$ \\
\hline & $0065 \_S D$ & 0518 & $38 / 65$ & 0962 & $15 / 26$ & $1515 \mathrm{c}$ & $39 / 60$ & 0099 (tlpA) & $11 / 26$ & 0859 & $46 / 71$ \\
\hline & 1307preTMM & 1678 (tlpA) & $17 / 44$ & 0135 (tlpA) & $23 / 50$ & $1790(\operatorname{tlpA})$ & $15 / 31$ & 0099 (tlpA) & $13 / 32$ & 1333 & $25 / 57$ \\
\hline & 1307postTMM & & $55 / 75$ & & $55 / 73$ & & $56 / 75$ & & $45 / 70$ & & $52 / 73$ \\
\hline Aer & 1012 & 1259 & $46 / 67$ & 1341 & $41 / 65$ & 0045 & $42 / 67$ & $0621^{j}$ & $19 / 44$ & 0696 & $50 / 71$ \\
\hline che $\mathrm{W}$ & 0332 & $0361^{b}$ & $71 / 85$ & 0319 & $70 / 81$ & 0792 & $67 / 81$ & 0391 & $53 / 79$ & 2082 & $58 / 79$ \\
\hline che $\mathrm{A}$ & 0331 & $0362^{\mathrm{b}}$ & $80 / 90$ & 0318 & $79 / 89$ & 0793 & $78 / 89$ & 0392 & $79 / 89$ & 2083 & $69 / 81$ \\
\hline $\operatorname{cheY}$ & 1193 & $0723^{b}$ & $38 / 65$ & 1020 & $39 / 66$ & 0459 & $39 / 65$ & 1067 & $11 / 19$ & 0415 & $64 / 86$ \\
\hline $\operatorname{cheB}$ & 0805 & $1025^{b}$ & $53 / 75$ & $1051^{\mathrm{e}}$ & $46 / 70$ & 0824 & $49 / 73$ & 0568 & $15 / 31$ & 1213 & $52 / 70$ \\
\hline che $\mathrm{R}$ & 0803 & $1024^{b}$ & $36 / 63$ & $1052^{f}$ & $42 / 70$ & 0825 & $39 / 65$ & 0664 & $14 / 30$ & 1212 & \\
\hline che $\mathrm{V}$ & 0330 & $0363^{b}$ & $68 / 87$ & 0317 & $70 / 87$ & 0794 & $70 / 87$ & 0393 & $47 / 69$ & 2084 & \\
\hline cheZ_H & 1051 & $0766^{\mathbf{c}}$ & $59 / 74$ & $1384^{c}$ & $50 / 62$ & $0560^{c}$ & $56 / 73$ & 0170 & $43 / 65$ & $2123^{c}$ & \\
\hline
\end{tabular}


${ }^{\mathrm{a}}$ : probable membrane protein Cj0952, ${ }^{\mathrm{b}}:$ CCo is used as the annotation for chemotactic proteins, ${ }^{\mathrm{c}}$ : conserved hypothetical protein; ${ }^{\mathrm{d}}: \mathrm{MCP}$ transducer/ sensor y box protein; ${ }^{\mathrm{e}}:$ putative CheB; f: putative CheR, ${ }^{\mathrm{f}}:$

carbamoyl-phosphate synthase, large subunit (carB); ${ }^{\mathrm{g}}$ : putative MCP, ${ }^{\mathrm{h}}: \mathrm{MCP}-\mathrm{like}$ protein Helicobacter pylori $\mathrm{P} 12 ;{ }^{\mathrm{i}}:$ Hemolysin secretion protein precursor; ${ }^{\mathrm{j}}:$ recombination and DNA strand exchange inhibitor protein or DNA mismatch repair protein (MutS); ${ }^{k}$ : sensor kinase _ RHPS. \%I/S Identical / Similar amino acids. 
a)

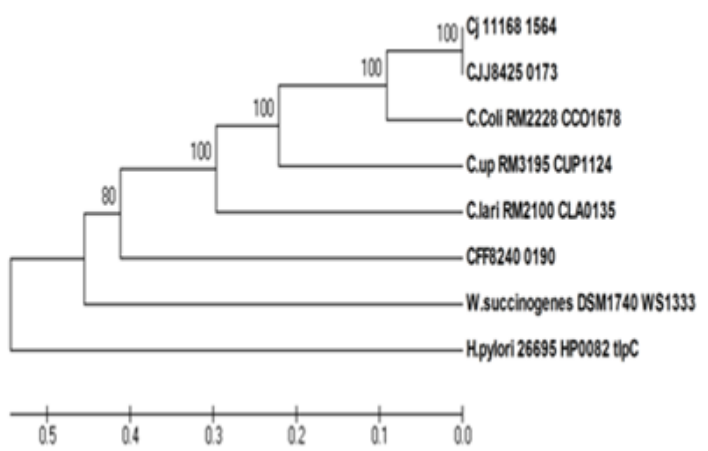

b)

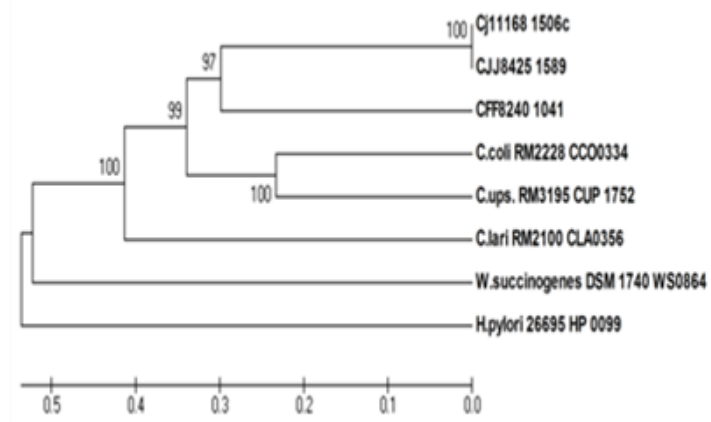

c)

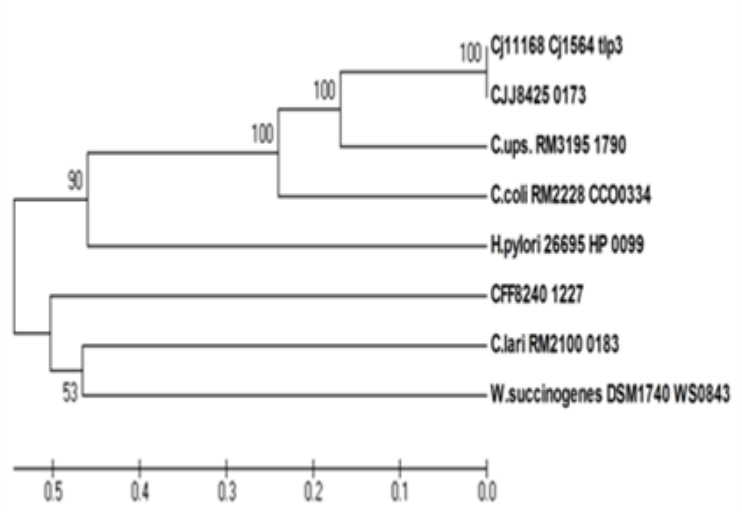

Fig (1) Dendogram based on alignment of $C$.fetus 82-40 Tlp protein CFF82-40-0190 (a), CFF82-40-1041 (b) and CFF82-40-1227 (c) with their respective orthologs in C. jejuni NCTC 11168, C. jejuni 84-25, C. coli RM2228, C. lari RM2100, C. upsaliensis RM3195, H. pylori 26696 and W. succinogenes DSM 1740. 